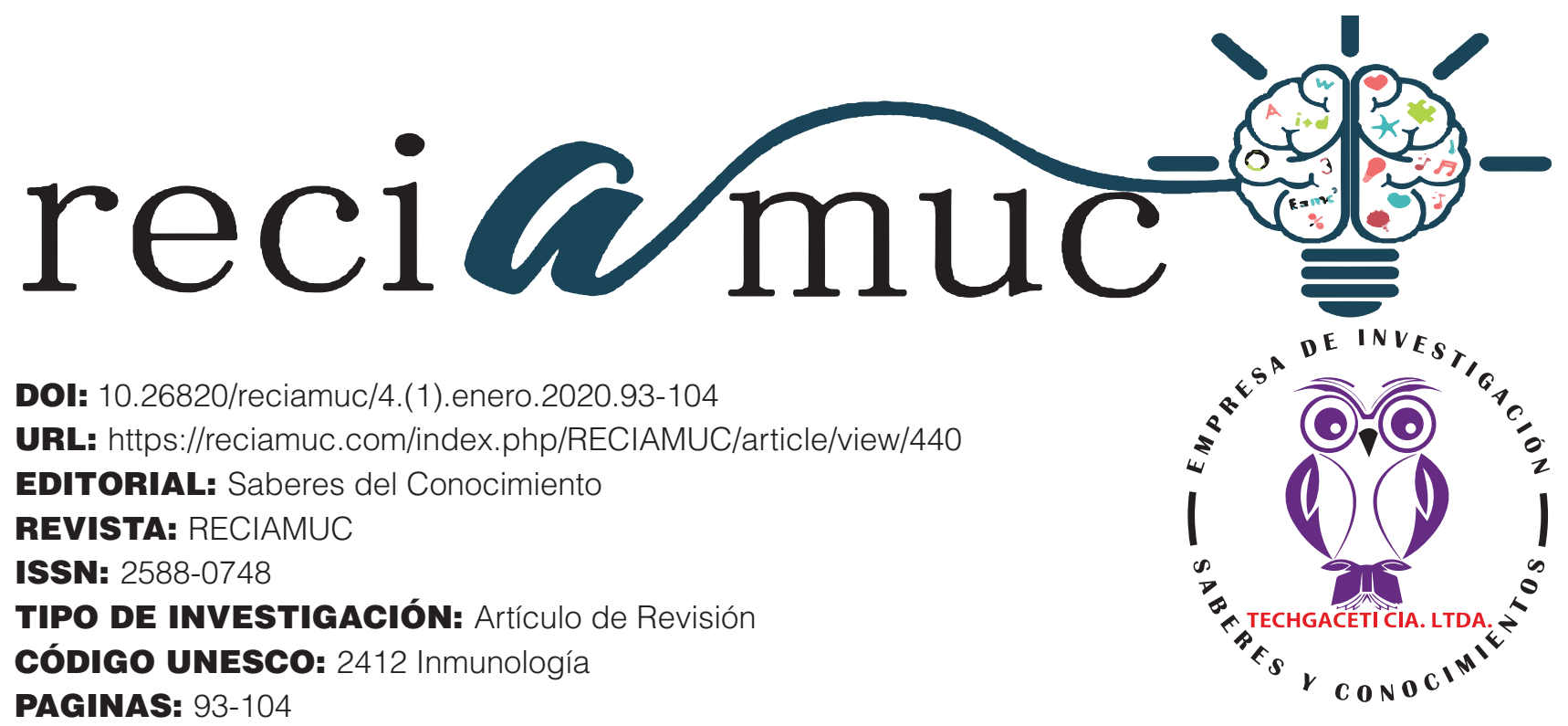

\title{
Beneficios Inmunológicos de la leche materna
}

\section{Immunological benefits of maternal care} Beneficios Inmunológicos do leite materno

\author{
Diego Armando Rodríguez Aviles'; Mirella Katuiska Barrera Rivera2; \\ Lady del Pilar Tihbanquiza Arreaga ${ }^{3}$; Antonella Fanny Montenegro Villavicencio ${ }^{4}$
}

RECIBIDO: 18/11/2019 ACEPTADO: 20/12/2019 PUBLICADO: 31/01/2020

1. Médico; Investigador Independiente; Guayaquil, Ecuador; diegoarmand_23@hotmail.com; (D) https://orcid. org/0000-0001-6916-7640

2. Médico; Investigador Independiente; Guayaquil, Ecuador; mir_bella88@hotmail.com; (D https://orcid.org/00000002-7766-410X

3. Médico; Investigador Independiente; Guayaquil, Ecuador; lady_flor05@hotmail.com; (iD https://orcid.org/00000003-4841-4803

4. Médico; Investigador Independiente; Guayaquil, Ecuador; anto.montenegrov@gmail.com; (D) https://orcid. org/0000-0002-5758-3994

CORRESPONDENCIA

Diego Armando Rodríguez Aviles

diegoarmand_23@hotmail.com

Guayaquil, Ecuador 


\section{RESUMEN}

La nutrición del neonatal es fundamental para el desarrollo biológico, por tal motivo la leche materna reviste una importancia como fuente de factores que favorecen el múltiples factores bio activos presentes en ella, las que permiten prevenir numerosas patologías a las que se enfrentan el neonato durante su crecimiento. La Organización Mundial de la Salud ha reconocido la exclusividad de lactancia materna durante los primeros 6 meses del neonatal como parte de las políticas de nutrición y salud infantil, que promueve a nivel mundial en aras de garantizar el desarrollo evolutivo del ser humano.

La leche materna contiene factores que modulan y promueven el desarrollo del sistema inmunitario infantil, formada por lípidos, proteínas, hidratos de carbono, vitaminas y factores inmunológicos, producida de forma natural orgánica por la glándula mamaria; la misma evoluciona y se interrelaciona proporcionalmente a la necesidad del niño. Las propiedades de la leche materna y la evolución de su composición en concordancia con el crecimiento del niño se refiere a la lactancia como principal elemento de desarrollo del sistema inmune del neonatal. De tal forma, es menester identificar la proporción de esta influencia, así como el requerimiento de alimentos y nutrientes complementarios durante el crecimiento del infante, para garantizar los nutrientes y proteicos requeridos en el desarrollo de defensas inmunológicas durante la etapa de crecimiento. En tal sentido, el siguiente estudio tiene como propósito analizar la composición de la misma y las diversas hipótesis que se platean sobre cómo éstos influyen en la protección de determinadas patologías, así como revisar algunos estudios que se contraponen. en torno a la disyuntiva sobre sí la misma, coadyuva en la prevención de cuadros clínicos alérgicos y asmático, o por el contrario inciden en la vulnerabilidad y propensión del infante, dada la transmisión genética de las mismas.

Palabras clave: Leche Materna, Lactancia Exclusiva, Lactancia Materna, Glándula Mamaria, Cáncer de Mama, Sistema Inmune, Inmunológico, Neonatal, Infante, Nutrición Neonatal.

\section{ABSTRACT}

The neonatal nutrition is fundamental for the biological development, for this reason breast milk is important as a source of factors that favor the multiple bioactive factors present in it, which allow to prevent numerous pathologies faced by the newborn during its increase. The World Health Organization has recognized the exclusivity of breastfeeding during the first 6 months of the neonatal as part of the nutrition and child health policies, which it promotes worldwide in order to guarantee the evolutionary development of the human being.

Breast milk contains factors that modulate and promote the development of the children's immune system, consisting of lipids, proteins, carbohydrates, vitamins and immune factors, produced naturally organic by the mammary gland; it evolves and interrelated proportionally to the child's need. The properties of breast milk and the evolution of its composition in accordance with the growth of the child refers to breastfeeding as the main element of development of the neonatal immune system. Thus, it is necessary to identify the proportion of this influence, as well as the requirement of complementary foods and nutrients during the infant's growth, to guarantee the nutrients and proteins required in the development of immunological defenses during the growth stage. In this sense, the following study aims to analyze the composition of the same and the various hypotheses that are planted on how they influence the protection of certain pathologies, as well as review some studies that are opposed. around the dilemma about itself, it helps in the prevention of allergic and asthmatic clinical conditions, or on the contrary they affect the vulnerability and propensity of the infant, given their genetic transmission.

Keywords: Breast Milk, Exclusive Breastfeeding, Breastfeeding, Breast Gland, Breast Cancer, Immune, Immune, Neonatal, Infant, Neonatal Nutrition.

\section{RESUMO}

A nutrição neonatal é fundamental para o desenvolvimento biológico, por isso o leite materno é importante como fonte de fatores que favorecem os múltiplos fatores bioativos presentes, que permitem prevenir inúmeras patologias enfrentadas pelo recém-nascido durante o seu aumento. A Organização Mundial da Saúde reconheceu a exclusividade do aleitamento materno durante os primeiros 6 meses do período neonatal como parte das políticas de nutrição e saúde infantil, promovidas mundialmente, a fim de garantir o desenvolvimento evolutivo do ser humano.

O leite materno contém fatores que modulam e promovem o desenvolvimento do sistema imunológico infantil, constituído por lipídios, proteínas, carboidratos, vitaminas e fatores imunológicos, produzidos naturalmente orgânicos pela glândula mamária; evolui e se inter-relaciona proporcionalmente à necessidade da criança. As propriedades do leite materno e a evolução de sua composição de acordo com o crescimento da criança referem-se à amamentação como o principal elemento de desenvolvimento do sistema imunológico neonatal. Assim, é necessário identificar a proporção dessa influência, bem como a necessidade de alimentos e nutrientes complementares durante o crescimento do bebê, para garantir os nutrientes e proteínas necessários no desenvolvimento de defesas imunológicas durante o estágio de crescimento. Nesse sentido, o estudo a seguir tem como objetivo analisar a composição das mesmas e as várias hipóteses que são plantadas sobre como elas influenciam a proteção de determinadas patologias, além de revisar alguns estudos que se opõem. em torno do dilema sobre si mesmo, ajuda na prevenção de condições clínicas alérgicas e asmáticas ou, pelo contrário, afeta a vulnerabilidade e a propensão do bebê, dada sua transmissão genética.

Palavras-chave: Leite materno, aleitamento materno exclusivo, aleitamento materno, glândula mamária, câncer de mama, imunológico, imunológico, neonatal, infantil, nutrição neonatal. 


\section{Introducción}

El periodo de mayor vulnerabilidad del ser humano es la infancia, etapa de maduración y de desarrollo de los órganos vitales y del sistema de defensa inmunológico que permitirá combatir futuros cuadros clínicos. De tal manera, que la nutrición del neonatal es fundamental para su desarrollo biológico. En efecto, la leche materna reviste una importancia como fuente de factores que favorecen el desarrollo del sistema inmune, existen numerosas patologías que podrían prevenirse gracias a la combinación de los diversos componentes bio activos presentes en ésta.

La leche materna es inocua y contiene anticuerpos que ayudan a proteger a los lactantes de enfermedades frecuentes de la infancia como la diarrea y la neumonía, que son las causas principales de la mortalidad en la niñez en todo el mundo, tal como lo expresa, la Organización Mundial de la Salud; "Si prácticamente todos los niños fueran amamantados, cada año se salvarían unas 820.000 vidas infantiles". (Bahl, Barros, \& Franca, 2016)

La leche materna contiene múltiples factores que modulan y promueven el desarrollo del sistema inmunitario infantil, incluyendo su potencial papel protector contra la enfermedad alérgica, es esta entre otras la causa fundamental de que la OMS promueva activamente la lactancia natural exclusiva durante los primeros 6 meses del infante, como la mejor forma de nutrición.

En el presente estudio se analizarán la composición funcional de la leche materna, para precisar los beneficios de éstos tanto para el niño como para la madre, así como se identificará las principales patologías que previene la lactancia materna exclusiva. Por último se revisarán los planteamientos dicotómicos desarrollados en torno al impacto que la lactancia materna tiene en la prevención de alergias, con el objeto de identificar las propiedades de la leche materna en el sistema inmunológico.

\section{Método}

El presente estudio se ha llevado a cabo bajo la metodología de investigación documental, revisando mas de 50 fuentes bibliográficas, y analizándolas bajo los criterios de inducción e inferencias, en tono a las los planteamientos mas comunes respecto a la Lactancia Materna, la leche materna y sus componentes, el sistema inmune infantil y los beneficios que representan la composición de la leche materna en la evolución del sistema inmunológico en el ser humano.

Se garantizan la heterogeneidad de los hallazgos teóricos y prácticos analizados en el presente estudio, con la revisión de diversas fuentes: medios electrónicos, libros científicos, revistas e investigaciones en la materia. Se consideraron los aportes mas relevantes de especialistas y los planteamientos teóricos de éstos para resaltar ideas consensuadas y plasmar las disyuntivas que se establecen en torno a cuales son aquellas patología que efectivamente previene la lactancia materna y cuales son aquellas otras en donde se generan disyuntiva en cuanto a su capacidad preventiva, estudios encontrados que dan paso a futuras investigaciones y casos de estudio.

\section{Resultados}

Beneficios Inmunológicos de la leche materna

La leche está formada por lípidos, proteínas, hidratos de carbono, vitaminas y factores inmunológicos; es producida por la glándula mamaria. La glándula mamaria es un conjunto especializado de glándulas apocrinas (sudorípara) que en el curso evolutivo modifican su secreción produciendo leche.

Es importante observar las Fases de la Lactogénesis:

- Lactogenesis I: Diferenciación citológica y enzimática de las células del epitelio alveolar. En la mujer embarazada aumenta la producción de gotas de gra- 
sa, que eleva el tamaño de las células mamarias, la glándula queda en reposo hasta el alumbramiento de la placenta, debido a los altos niveles de progesterona circulante.

Lactogenesis II: Secreción de todos los componentes de la leche, fase en la que comienza la producción de leche de forma más abundante.

- Lactogenesis III: se mantiene la secreción láctea establecida por el reflejo de succión del recién nacido.

La leche humana es definida como un "fluido vivo que se adapta a los requerimientos nutricionales e inmunológicos del niño a medida que éste crece y se desarrolla" (Shellhorn \& Valdés, 1995) Contiene un complejo conjunto de factores inmunes y puede ser vista como la interface entre el sistema inmunológico materno y del lactante. Sus nutrientes funcionales ayudan a facilitar el microambiente necesario para el desarrollo del sistema inmune y la maduración intestinal.

Al realizar examen microscópico del intestino delgado fetal antes del nacimiento se observa un epitelio inmaduro y escasas células linfoide; después de que el niño nace se aplica el examen de la misma sección del intestino delgado, un vez que se inicia la lactancia materna, el estudio revela un epitelio maduro, proliferante, con diferenciación de enterocitos y abundante tejido linfoide. Evidencia del valor nutritivo de las propiedades.

La composición de la leche materna según las etapas de la lactancia varía, por esto se refiere a ella como un elemento vivo que evoluciona y se interrelaciona proporcionalmente a la necesidad del niño. "Durante la etapa del destete, la leche involuciona y pasa por una etapa semejante al calostro al reducirse el vaciamiento". (Shellhorn \& Valdés, 1995) La composición de la leche materna evoluciona con el tiempo para ayudar al niño a adaptarse al dinámico medio extrauterino. Por ejemplo, el calostro contiene múltiples factores tróficos que ayudan a la proliferación de enterocitos en comparación con la leche humana madura. La composición del calostro de la leche materna prematura es diferente que la de la leche materna de término, con mayores niveles de factor de crecimiento epidérmico.

En este sentido (Iyengar \& Walker, 2013) plantea que "Los lactantes no son capaces de producir sus propios niveles de protección hasta casi 30 días después del nacimiento. En consecuencia, la IgAs está en sus niveles más altos en la leche materna durante la fase de calostro, cuando el niño necesita más a esta proteína inmune."

\section{Composición de la Leche Materna según las Etapas de la lactancia}

La composición de la leche materna varía con individualidades genéticas, tiempo de gestación y lactancia, con los hábitos dietéticos y el estado nutricional de la madre que lacta. El contenido celular de la leche depende de varios factores, como la plenitud de la glándula mamaria, la etapa de la lactancia, el estado de salud de la díada madre/bebé, la permeabilidad de la membrana basal y el desarrollo del epitelio mamario.

"Esto quiere decir que existe una gran heterogeneidad en la composición de la leche de una mujer a otra, y que se modifica al adaptarse a las necesidades de su bebé". Tal como lo menciona (Aguilar Cordero, y otros, 2016)

Las modificaciones detectadas en la leche humana corresponden con las variaciones de las necesidades de los lactantes para el crecimiento, según la composición de la leche humana se distingue 4 tipos: 
Tabla 1. Clasificación de la leche materna según las etapas de lactancia
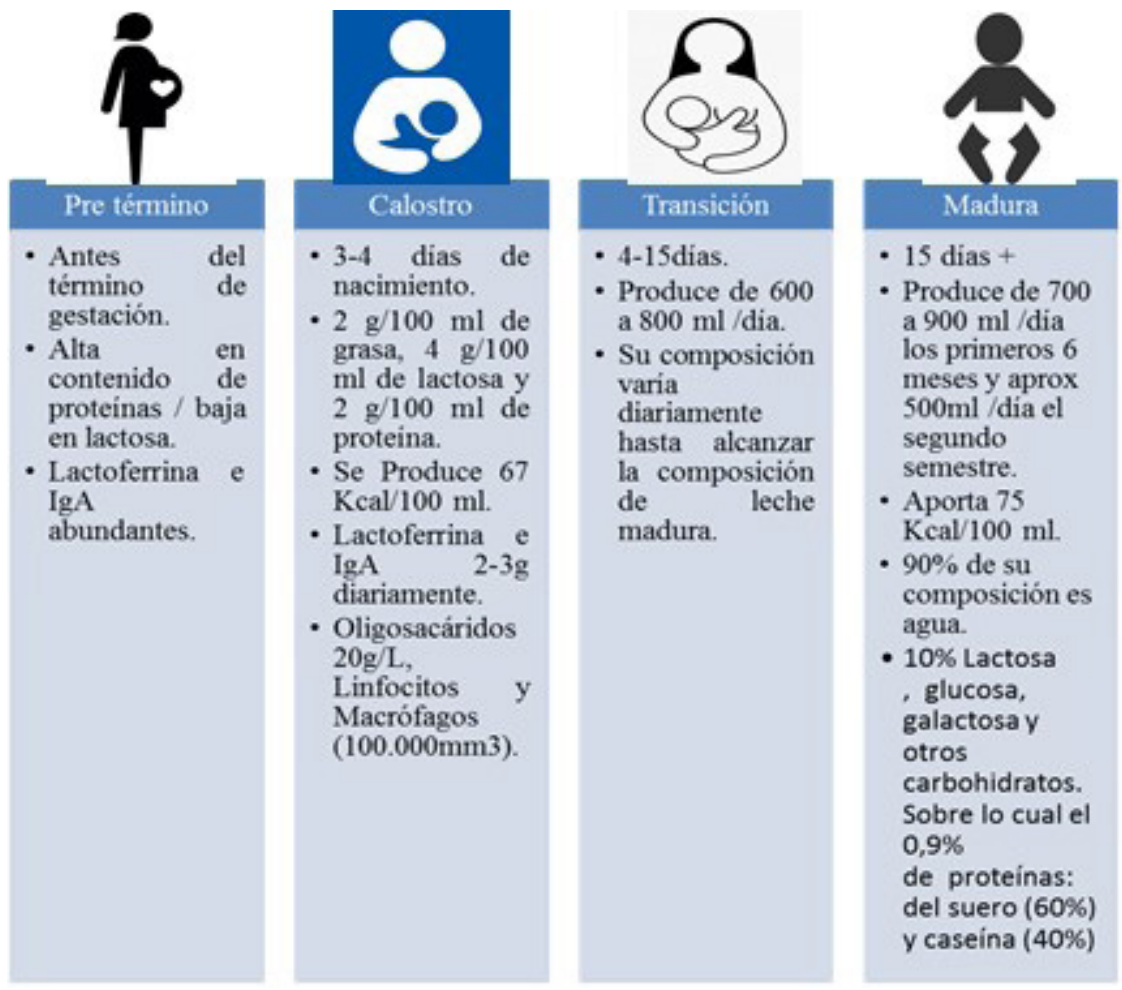

Fuente: Autores 2020

Tal como podemos observar en la Tabla 1, la leche de "pre término" contiene un mayor contenido de proteínas vitales para un bebé prematuro, que requiere mayor proteicos para su madurez, no obstante un recién nacido con peso $<1,5 \mathrm{~kg}$ requiere complementar su nutrición con otros elementos tales como expresa Schandler,1989, citado por UNICEF (Shellhorn \& Valdés, 1995) "fortificadores de leche materna"

La composición del calostro es más rica en inmunoglobulinas y proteínas que grasa en general, en relación con la leche transaccional y madura, lo que facilita en el infante la protección. De acuerdo a la composición, se plantean los siguientes beneficios en el sistema inmune:

- Los antioxidantes y las quinonas protegen del daño oxidativo y la enfermedad hemorrágica

- Las inmunoglobulinas (IgA) cubren el revestimiento interior inmaduro del tracto digestivo, previniendo la adherencia de

bacterias, virus, parásitos y otros patógenos

- Los factores de crecimiento estimulan la maduración de los sistemas propios del niño

La Leche de transición en relación al calostro posee mayor contenido de lactosa, grasas, calorías y vitaminas hidrosolubles y "disminuye en proteínas, inmunoglobulinas y vitaminas liposolubles".

La leche materna y sus beneficios inmunológicos de acuerdo a los tipos:

El sistema inmune del recién nacido está expuesto a microorganismos extraños a sistema, el $90 \%$ de la de las infecciones que afectan a los seres humanos utilizan la mucosa como puerta de entrada; la capacidad inmune moduladora que contiene la leche materna es fundamental en el desarrollo y madurez del sistema defensa. En efecto, se ha establecido "la Lactancia Materna Exclusiva" durante los primeros 6 meses de

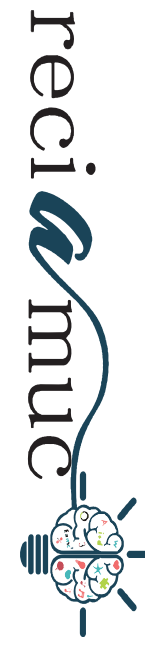


vida como una recomendación de la OMS a nivel mundial y se ha generado un código internacional para reglamentar el uso de lácteos y fórmulas durante este periodo del infante. En la tabla 2 se puede observar la clasificación de los compuestos con propiedades inmunológicas presentes en la leche materna.

Tabla 2. Composición de la Leche Materna

\begin{tabular}{|c|c|c|c|}
\hline $\begin{array}{l}\text { Compuestos } \\
\text { antimicrobianos }\end{array}$ & $\begin{array}{l}\text { Compuestos de } \\
\text { tolerancia }\end{array}$ & $\begin{array}{l}\text { Compuestos de } \\
\text { desarrollo del } \\
\text { sistema inmune }\end{array}$ & $\begin{array}{l}\text { Compuestos } \\
\text { anti-inflamatorios }\end{array}$ \\
\hline $\begin{array}{l}\text { - Inmunoglobulinas } \\
\text { (slgA, slgG, } \\
\text { slgM) } \\
\text { - Lactoferrina, } \\
\text { lactoferricina B y } \\
\text { - } \text { - Lizozima } \\
\text { - Lactoperoxidasa } \\
\text { - Haptocorrina } \\
\text { - Mucinas } \\
\text { - Ácidos grasos }\end{array}$ & $\begin{array}{l}\text { - } \quad \text { Citoquinas (IL- } \\
10 \text { y TGF-beta) } \\
\text { - } \quad \text { Anticuerpos } \\
\text { antiidiotípicos }\end{array}$ & $\begin{array}{l}\text { - Macrófagos } \\
\text { - Neutrófilos } \\
\text { - Linfocitos } \\
\text { - Citoquinas } \\
\text { - Factores de } \\
\text { crecimiento } \\
\text { - Hormonas } \\
\text { - Péptidos } \\
\text { lácteos }\end{array}$ & $\begin{array}{l}\text { - Citoquinas (IL- } \\
10 \text { y TGF-beta) } \\
\text { - Receptores } \\
\text { antagonistas } \\
\text { de IL-1 } \\
\text { - Moléculas de } \\
\text { adhesión } \\
\text { - Ácidos grasos } \\
\text { de cadena } \\
\text { larga } \\
\text { - Hormonas y } \\
\text { factores de } \\
\text { crecimiento } \\
\text { - Lactoferrina }\end{array}$ \\
\hline
\end{tabular}

Fuente: Journal of Nutrition,2005

Propiedades inmunológicas de los componentes de la Leche Materna:

- Inmunoglobulina A Secretora (slgA), propiedades de acción anti-infecciosa sobre antígenos específicos.

- Lactoferrina (Lf) Inmunomodulación, quelación de hierro, poseen propiedades de acción antimicrobiana, anti-adhesiva, trófica del crecimiento intestinal.

- La Lisozima, Lisis bacteriana, inmunomodulación.

- Caseína, es anti-adhesiva protegiendo la flora bacteriana.

- Citoquinases es principalmente anti-inflamatorias, promueve el crecimiento de las células epiteliales, supresión de la función de los linfocitos, y promueve el crecimiento de los nervios.
- Enzimas, previenen la oxidación lipidia.

- La respuesta inmunológica, en mucosas, ante un estímulo causa sensibilización de linfocitos T y B y producción de anticuerpos, especialmente IgA que se secreta en mucosas maternas y en la leche materna, integrando la inmunidad de las mucosas madre-hijo.

\section{Respuesta inmunológica: el estímulo}

Los antígenos ingeridos por la madre, son capturados en el intestino por las células M, quienes los transportan a las placas de $\mathrm{Pe}$ yer donde los macrófagos los presentan a los linfocitos T. Estos estimulan a los linfocitos $\mathrm{B}$, que se clonan y migran a los ganglios mesentéricos.

- Producción de anticuerpos IgA.

- Los linfocitos B viajan a través del con- 
ducto torácico y llegan a las mamas y se transforman en células plasmáticas que producen IgAs. Primero producen monómeros de IgA que se unen en diá- metros a los que se unen en diámetros a los que se une una proteína (componente secretor) que les da protección y resistencia a la digestión enzimática.

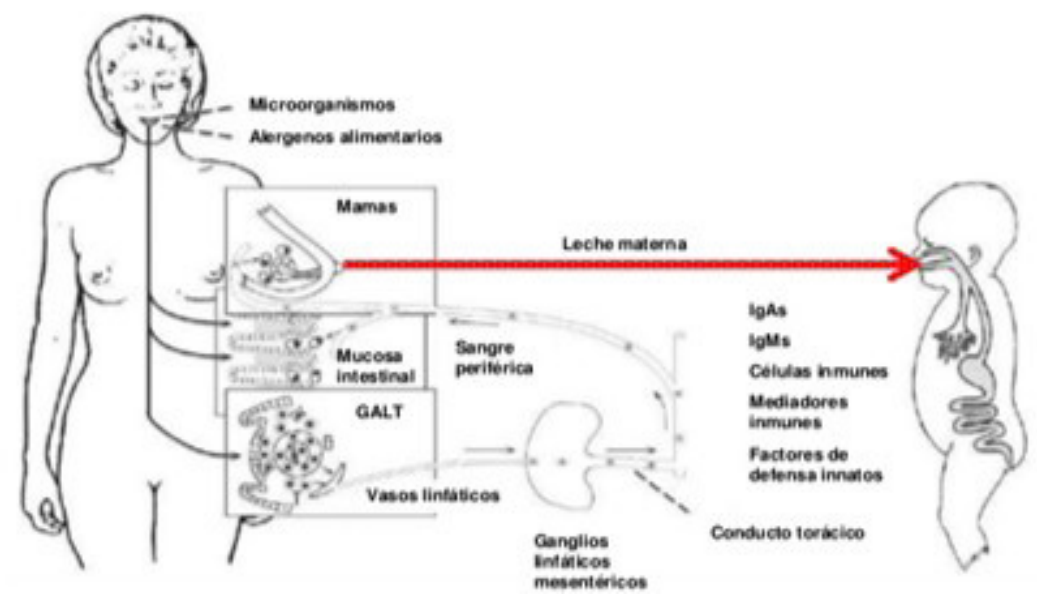

Figura 1. Integración de la inmunidad de mucosas madre-hijo

Fuente: Autores 2020

- La leche humana tiene factores antimicrobianos que disminuyen las infecciones agudas en los niños.

- También tiene factores antiinflamatorios e inmunomoduladores que disminuyen problemas autoinmunes o alergias.

- Influye activamente sobre el metabolismo y su microflora, confiriéndole múltiples modos de protección frente a los patógenos. (Nylander, 2005), En su libro Maternidad y Lactancia exponen: "la IgA se adhiere a las mucosas del largo canal intestinal y de ese modo lo tapiza por dentro. Y allí se queda, como un atrapamoscas que se encarga de las bacterias y los virus que puedan pasar".

Es importante acotar que (Red Informática de Medicina Avanzada) señala el planteamiento realizado por la Academia Americana de Pediatría (AAP) al respecto: "En los 42 países en desarrollo en los que se producen el $90 \%$ de las muertes de niños a nivel mundial, la lactancia materna exclusiva durante 6 meses y la combinación de la lactancia con alimentos complementarios después del año de vida del bebé, es la in- tervención más eficaz, con el potencial de prevenir más de un millón de muertes infantiles por año, lo que equivale a la prevención de $13 \%$ de la mortalidad infantil en el mundo".

La lactancia materna es una de las formas más eficaces de asegurar la salud y la supervivencia de los niños. A nivel mundial, solo un $40 \%$ de los lactantes menores de seis meses reciben leche materna como alimentación exclusiva.

- El efecto de leche materna se manifiesta contra las siguientes bacterias, virus, parásitos y hongos: E. coli, Shigela, Salmonella, Campylobacter, Vibrio cholerae, $\mathrm{H}$. influezae, $\mathrm{S}$. pneumoniae, C. difficile, K. pneumoniae, C. botulinum Rotavirus, virus sincitial respiratorio, Poliovirus, Influenza, Citomegalovirus, V I $\mathrm{H}$, Giardia, Candida Albicans.

- Estudios recientes han demostrado que el epítope del azúcar Lewis X (Le2), comúnmente hallado en la leche materna, puedo inhibir la captura y transferencia del HIV-1 a los linfocitos T, lo cual influye en la presentación antigénica del pató- 
geno.

Las proteínas de la leche humana brindan los aminoácidos que el lactante requiere para su rápido crecimiento. Pero, también juegan un papel importante en la digestión, captación de otros nutrientes y protección inmunológica (Shellhorn \& Valdés, 1995)

Beneficios nutricionales de la lactancia materna:

(1) Desarrollo del intestino y sus funciones: al nacimiento, el intestino neonatal es inmaduro y la leche materna contiene nutrientes funcionales que proporcionan un microambiente para la protección y maduración intestinal. (ver imagen 2)

- Incremento de las funciones del sistema inmunológico para la defensa en contra de bacterias, virus y levaduras: La leche temprana, y más aún, la leche de las madres de prematuros contiene mayor concentración de factores tróficos, de células fagocíticas y de IgAs. Los cuales favorecen la maduración intestinal.

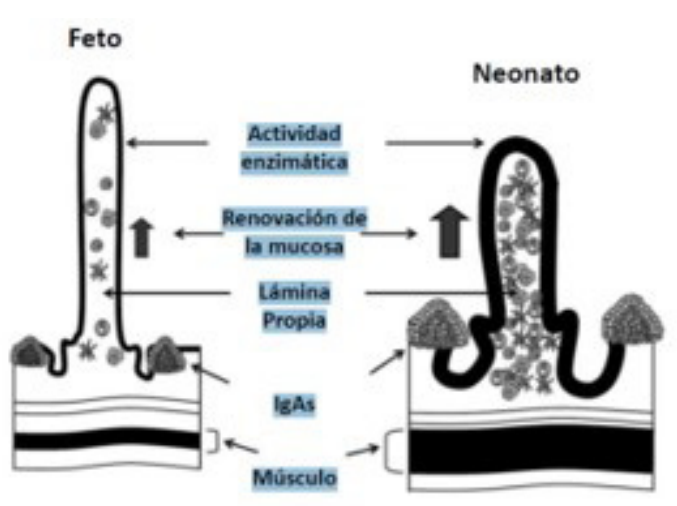

Figura 2. Desarrollo intestinal del neonato

Fuente: Walker A Breast Milk as the gold standard for protective nutrients. J Pediatr 2010

\section{Enfermedades que previene la lactancia materna}

Por su parte el Dr. Julio Basulto (Basulto, 2015) refiere alguna de las enfermedades mas frecuentes que puede prevenir la lactancia materna en una relación dosis-respuesta

- Bronquiolitis por virus respiratorios.

- Dermatitis atópica.

- Diabetes tipo 1 o tipo 2.

- Enfermedad celíaca.

- Enfermedad inflamatoria intestinal.

- Enterocolitis necrotizante.

- Gastroenteritis.

- Infección del tracto respiratorio superior o inferior.

- Leucemia.

- Obesidad.

- Otitis media.

- Síndrome de muerte súbita del lactante

Factores inmunológicos en la leche materna y desarrollo de enfermedad atópica:

El efecto de la lactancia materna en el desarrollo de la inmunidad alérgica no es concluyente; tal como plantea (lyengar \& Walker, 2013)"Se piensa que algunos elementos de la leche materna protegen al niño de desarrollar enfermedades alérgicas, tales como el eccema y el asma, mientras que otros factores están implicados en el aumento de la susceptibilidad alérgica. Las razones para esta controversia residen en la complejidad 
de la interacción entre la leche materna y el ambiente intestinal y el sistema inmunológico del lactante."

La naturaleza de la leche materna guarda sincronía con las necesidades y la evolución del cambio del lactante por lo cual tienen implicaciones importantes sobre el desarrollo del sistema inmune. Sin embargo las alteraciones en la interacción entre la leche materna y el sistema inmune del lactante pueden de igual forma, contribuir al desarrollo de algunas enfermedades.

De tal forma, que se deduce que así como la leche materna es fundamental en el desarrollo del sistema inmunológico del infante, la carencia de algunos componentes específicos puede predisponer la inflamación intestinal, o en el caso de algunas lactantes con cuadros alérgicos, es menester analizar si esto tiene incidencia en el desarrollo de estos cuadros clínicos en el infante. "Son necesarios otros estudios en humanos para explorar cómo las diferencias individuales en la composición de la leche materna podrían predisponer a condiciones de inflamación intestinal, tales como la enfermedad alérgica."

En este sentido, las Inmunoglobulinas IgA secretora (IgAs), está alterada en las madres lactantes con enfermedad alérgica, específicamente dirigida contra los antígenos del ambiente materno, sin embargo se hallaron menores niveles de IgAs en el calostro de madres alérgicas en comparación con las madres no alérgicas. No obstante, otro estudio demostró que los niveles de IgAs en la leche materna no predijeron el desarrollo de enfermedad alérgica en los niños hasta los 18 meses de edad. Estas diferencias demuestran la complejidad de la relación entre los factores de la leche materna y el desarrollo de enfermedades alérgicas, de tal manera que los estudios pormenores respecto al impacto especifico de la leche materna en la evolución del cuadro alérgico, debe orientar el análisis a profundidad.

El CD14 es el componente soluble del re- ceptor tipo Toll 4 (RTT4) y juega un papel importante en la inmunidad innata, se ha identificado que en la etapa del calostro su nivel es elevados pero disminuyen en las siguientes fases de la lactancia. Este componente generalmente junto a los lipopolisacáridos (LPS) de bacterias Gram-negativas y enterocitos intestinales, inician la cadena de eventos que alerta al brazo adaptativo del sistema inmunológico del infante. De tal manera, que su disminución y ausencia reducirá a su vez la eficacia de la respuesta.

Señala (lyengar \& Walker, 2013) "El CD14 puede estar relacionado con la enfermedad alérgica a través de la "hipótesis de la higiene". Esta teoría bien conocida propuesta hace más de 2 décadas atrás postula que la exposición temprana a LPS (o endotoxinas) disminuye el riesgo de desarrollar enfermedad alérgica"

No obstante otros estudios señalan que si la madre presenta síntomas de atopia han habido hallazgos de menores niveles de CD14 soluble en el calostro, asi como disminución en la leche materna luego de los 3 meses del parto. ". Las citoquinas tolerogénicas, como el factor de crecimiento transformante beta (FCT- $\beta$ ) y la 10-IL, están implicadas en la supresión de la respuesta inflamatoria y son las citoquinas predominantes en la leche materna.

Otra clase de sustancias protectoras halladas en la leche materna son los ácidos grasos poli insaturados y los oligosacáridos no digeribles. Ambos estimulan la proliferación de bacterias colonizantes necesaria para activar el sistema inmunológico del recién nacido; dichos ácidos grasos puede determinar si la leche materna promueve o protege contra la enfermedad alérgica. Estudios en humanos han demostrado resultados contradictorios con respecto al desarrollo de atopia y el contenido de ácidos grasos. Sin embargo, estos estudios han sido limitados por la variación de la dieta y los antecedentes genéticos, las infecciones, y otras influencias ambientales. También se ha de- 
mostrado que los oligosacáridos de la leche estimulan preferentemente a las bifidobacterias. Esta cepa bacteriana colonizante, en presencia de oligosacáridos específicos de la leche, produce factores que mejoran la actividad de la célula T reguladora y promueven la tolerancia intestinal.

La fisiopatología de esta condición, así como la forma en que otros antígenos alimentarios que se encuentran en la leche materna llevan a la sensibilización y a la enfermedad alérgica en lactantes, no se ha determinado. Sin embargo, es posible que estas proteínas extrañas, en presencia de citoquinas proinflamatorias y otros factores inmunes, predispongan a los niños a esta condición. En contraste, es probable que estas mismas proteínas alimentarias, en presencia de otros factores de la leche tales como el FCT- $\beta$ y la 10-IL, conduzcan a la tolerancia mucosa. Se necesitan estudios adicionales para dilucidar el papel de estos factores de la leche materna en el desarrollo de la sensibilización o bien de la tolerancia del lactante. Los estudios que investigan estos componentes de la leche materna y la respuesta intestinal infantil en ambos resultados facilitarán una mejor comprensión del impacto de la lactancia materna en la enfermedad alérgica infantil.

\section{Resultados}

La mayoría de los expertos coinciden en que la lactancia materna es el método de alimentación más eficaz y apropiado para los lactantes, y que la lactancia materna exclusiva es efectiva para minimizar el riesgo de desarrollar diversas patología, entre las cuales enfermedades alérgicas. Aun y cuando varios estudios recientes han demostrado que la lactancia materna o bien no tiene efecto protector o predispone a los lactantes al desarrollo de atopia.. Se halló que el efecto protector de la lactancia materna fue observado sólo cuando el análisis se restringió a los estudios que utilizaron personal médico para evaluar los resultados clínicos, tales como la dermatitis atópica
Como se mencionó anteriormente, estos factores incluyen la frecuencia de la lactancia materna, incluyendo si los niños fueron exclusivamente amamantados, aunado a las prácticas de alimentación, por ejemplo, madres atópicas con diferentes prácticas de lactancia materna que las madres no atópicas. De tal forma qe se requieren futuros estudios de cohorte de nacimiento para examinar la incidencia de la enfermedad atópica y comparar directamente a los lactantes alimentados con fórmulas hidrolizadas durante un período de tiempo prolongado. La incidencia de enfermedad alérgica, y no simplemente la sensibilización, debe evaluarse en el tiempo con evaluaciones clínicas, más que con el uso de cuestionarios de auto-reporte.

\section{Conclusiones}

La leche materna contiene múltiples factores que modulan y promueven el desarrollo del sistema inmunitario infantil, incluyendo su potencial papel protector contra la enfermedad alérgica. Estos factores incluyen inmunoglobulinas tales como la IgA secretoria, proteínas antimicrobianas tales como el CD14, citoquinas, y ácidos grasos. Además de proporcionar protección contra infecciones que pueden promover la enfermedad atópica, la lactancia materna también promueve el establecimiento de una microbiota intestinal que puede proteger contra la enfermedad atópica.

La lactancia materna exclusiva, además de tener otros beneficios bien reconocidos, puede proteger contra la aparición de diversas patologías mencionadas y ente ellas la dermatitis atópica mediante la disminución de la exposición a alérgenos externos. Tolerancia que se genera gracias a la presencia de factores inmunes co-estimulantes.

En resumen, aunque el efecto general de la lactancia materna en la enfermedad alérgica sigue siendo desconocido, la mayoría de los profesionales coinciden en que la lactancia materna exclusiva es el método preferido de nutrición para todos los niños 
en base a sus otros posibles beneficios. Los autores consideran que la leche materna es protectora contra la enfermedad alérgica, y que los estudios hasta la fecha han demostrado resultados mixtos debido a la heterogeneidad en los métodos de estudio. Algunos de los efectos inmunomoduladores predominantes de la leche materna, tales como los del FCT- $\beta$ y la IL 10, que están implicados en la supresión de la respuesta inflamatoria, apoyan esta hipótesis.

La leche materna es una fuente importante de factores que favorecen el desarrollo del sistema inmune infantil, y se consideraría además como un factor de protección contra la enfermedad alérgica en sus diversas presentaciones. Los numerosos beneficios de la lactancia materna exclusiva para el lactante en desarrollo hacen indispensable que los profesionales fomenten esta forma de alimentación, y que la madre lactante presuponga las condiciones nutricionales requeridas para garantizar todas as propiedades evaluadas en el presente estudio, que efectivamente desarrollen el sistema inmunológico.

\section{Bibliografía}

Aguilar Cordero, M. J., Baena Garcia, L., Sánchez López, A. M., Guisado Barrilao, R., Hermoso Rodriguez, E., \& Mur Villar, N. (2016). Beneficios inmunológicos de la leche humana para la madre y el niño. España.

Baeza Bacab, M. A. (2016). Inmunología de la leche humana. Yucatán: Universidad Autónoma de Yucatán.

Bahl, B., Barros, A., \& Franca, ,. S. (2016). "Breastfeeding in the 21st Century: Epidemiology, Mechanisms and Lifelong Effect".

Basulto, J. (19 de Enero de 2015). Espacio abierto, psicología y nutrición. Recuperado el enero de 2020, de http://psicologiaynutricion.es/?p=923

Clínica Alemana. (07 de Marzo de 2019). Inmunología de la leche humana. Mèxico: Colegio de Neonatólogos de Yucatán. Obtenido de http://neonatologosyucatan.org.mx/admin/uploads/filemanager/ inmunologia-leche-humana-neonatologos-1a76. pdf

Garcia López , R. (2011). Composición e inmunolo- gía de la leche humana. Acta Pediátrica de México.

Gómez Papi, A. (1997). Lactancia Materna en Prematuros. Boletín de la sociedad de pediatría de Asturias, Cantabria, Castilla y León.

González García, N. E. (s.f.). Lactancia Materna. En Familia, http://www.sld.cu/galerias/pdf/sitios/wi|liamsoler/en_familia_1_2_3_4_5_6_7_8_9.pdf.

lyengar, S. R., \& Walker, W. A. (23 de septiembre de 2013). Intra med. Recuperado el enero de 2020, de https://www.intramed.net/contenidover.asp?contenidoid $=79605$

Lactancia Materna. (2016). Lactancia Materna y Prematurez. Mèxico: Lactancia Materna. Obtenido de http://lactancia-materna-fmed.blogspot. com/2016/10/lactancia-materna-y-prematurez. $\mathrm{html}$

Nylander, G. (2005). Maternidad y Lactancia. Ediciones Granica S.A.

OMS. (2017). 10 datos sobre la lactancia materna. Ginebra, Suiza: Organización Mundial de la Salud. Obtenido de https://www.who.int/features/factfiles/ breastfeeding/es/

Red Informática de Medicina Avanzada. (s.f.). RIMA. Recuperado el enero de 2020, de https://www. rima.org/Noticia. aspx?ldNota $=2972$

Sabillón, F., \& Abdu, B. (1997). Compsición de la leche materna. Artículo de revisión, Honduras.

Shellhorn, C., \& Valdés, V. (1995). LA LECHE HUMANA, COMPOSICION, BENEFICIOS Y COMPARACIÓN CON LA LECHE DE VACA. Santiago de Chile: UNICEF. Recuperado el Enero de 2020, de https://www.unicef.cl/lactancia/docs/mod01/ Mod\%201beneficios\%20manual.pdf

Vasquez Hidalgo, A. (2000). Propiedades Antimicrobianas de la Leche Materna Madura contra enterobacterias. El Salvador. 


\section{CITAR ESTE ARTICULO:}

Rodríguez Aviles, D., Barrera Rivera, M., Tibanquiza Arreaga, L., \& Montenegro Villavicencio, A. (2020). Beneficios inmunológicos de la leche materna. RECIMAUC, 93-104. doi:10.26820/reciamuc/4.(1).enero.2020.93-104

RECONOCIMIENTO-NOCOMERCIAL-COMPARTIRIGUAL CC BY-NC-SA

ESTA LICENCIA PERMITE A OTROS ENTREMEZCLAR, AJUSTARY CONSTRUIR A PARTIR DE SU OBRA CON FINES NO COMERCIALES, SIEMPRE $Y$ CUANDO LE RECONOZCAN LA AUTORÍA Y SUS NUEVAS CREACIONES ESTÉN BAJO UNA LICENCIA CON LOS MISMOS TÉRMINOS. 